\title{
Platelet-rich plasma treatment improves postoperative recovery in patients with pilonidal sinus disease: a randomized controlled clinical trial
}

\author{
Can Yahya Boztug ${ }^{1}$, Tulay Karaagac Akyol ${ }^{2}$, Cigdem Benlice ${ }^{1}$, Mehmet Ali Koc ${ }^{1}$, Beyza Doganay Erdogan³ \\ Osman Ilhami Ozcebe ${ }^{2}$, Mehmet Ayhan Kuzu and Cihangir Akyol ${ }^{1 *}$ (i)
}

\begin{abstract}
Background: Pilonidal sinus is a common health problem. The current study aimed to compare the impact of autologous platelet-rich plasma (PRP) with that of minimally invasive techniques in terms of pain reduction, return to daily activities, quality of life, and duration of wound healing after open excision and secondary closure.

Methods: Patients who were over 18 years old and had chronic PS disease between March 2018 and January 2019 were enrolled and randomly divided into three groups. Open surgery and moist dressings were applied to patients in group A. Open surgery followed by PRP application was performed on patients in group B. Group C underwent curettage of the sinus cavity followed by application of PRP. In this prospective randomized controlled study, patients completed questionnaires (including the Nottingham Health Profile (NHP), Short Form-36 (SF-36) and clinical information) before and after surgery. Demographics, preoperative characteristics, healing parameters, and quality-of-life scores were evaluated and calculated before and after surgery.
\end{abstract}

Results and conclusion: The cavity volume and wound-healing time were compared among the groups on postoperative days $0,2,3,4$, and 21 . Each patient was followed up throughout the process of wound healing, and follow-up was continued afterward to monitor the patients for recurrence. Due to the nature of the treatment that group $\mathrm{C}$ received, this group achieved shorter healing times and smaller cavity volume than the other groups. In contrast, the recovery time per unit of cavity volume was significantly faster in group B than in the other groups. Overall postoperative pain scores were significantly lower for both PRP groups (open surgery, group B; minimally invasive surgery, group C) than for group A ( $p<0.001)$ and showed different time courses among the groups. In the treatment of PS disease, PRP application improves postoperative recovery in that it speeds patients' return to daily activities, reduces their pain scores and increases their quality of life.

Trial registration The current study is registered on the public website ClinicalTrials.gov (ClinicalTrials.gov identifier number: NCT04697082; date: 05/01/2021).

Keywords: PRP, Pilonidal sinus, Quality of life, Pain

*Correspondence: cihangirakyol@gmail.com; cakyol@ankara.edu.tr

1 Department of Surgery, Ankara University Faculty of Medicine, Ankara, Turkey

Full list of author information is available at the end of the article

\section{Introduction}

Pilonidal sinus (PS) disease is a health problem that has been attacked using various treatment modalities since it was first described by Herbert Mayo in 1833. PS is most 
commonly diagnosed at 30 years of age, and $70-80 \%$ of patients are male [1].

Common morbidities after the surgical treatment of PS are pain, loss of productive work hours and wound infections owing to long healing times [2]. Therefore, the main goals of treatment are to accelerate healing by decreasing pain and to reduce the loss of productive work hours. Local administration of platelet-rich plasma (PRP), which contains growth factors (GFs), is a new method that has been reported to accelerate the healing process by $30-40 \%$ [3]. In this study, we aimed to investigate the effect of PRP on patients' pain scores, wound healing and quality of life in the process of treatment for PS disease.

\section{Methods}

\section{Trial design}

We designed the trial as a prospective, randomized controlled study. This study was conducted in accordance with the Declaration of Helsinki and was started after approval from the Ethics Committee of Ankara University Medicine Faculty in Ankara (Approval Number: 03-162-18). The current study is also registered on the public website ClinicalTrials.gov (ClinicalTrials.gov identifier number: NCT04697082; date: 05/01/2021). Informed consent was obtained from all the participants.

\section{Participants and eligibility criteria}

Patients who were over 18 years old and had chronic PS disease were included in the study. We excluded patients if they met any of the following criteria: acute abscess, anaemia, use of immunosuppressive drugs, haematological malignancy, bleeding disorders or recurrent PS disease.

\section{Randomization}

The patients were randomly divided into three groups. Simple randomization was performed using computergenerated random numbers in Microsoft Excel [4]. The interventions for each group are described below:

Group A: Open surgery and moist dressings were applied to these patients.

Group B: These patients underwent open surgery followed by PRP application. At the end of the procedure, the PRP-filled cavity was covered with PRP-impregnated gauze.

Group C: This group underwent curettage of the sinus cavity followed by PRP application. At the end of the procedure, the PRP-filled sinus tract was covered with PRPimpregnated gauze (Fig. 1).

\section{Medical history and demographics}

After enrolling the patients, we recorded their demographic data, including gender, age, education, comorbid diseases and drug use. Then, the Short Form-36 (SF-36) and Nottingham Health Profile (NHP) quality-of-life score questionnaires were administered before surgery. All patients were asked to remove the hair from the sacrococcygeal region using depilatory cream.

\section{Open surgical procedure}

Each patient entered the operating room, and after the administration of general anaesthesia, the patient was placed in the prone position. Then, the buttocks were pulled laterally using adhesive bands to enable the removal of the diseased area. The sacrococcygeal region was cleaned and disinfected with $10 \%$ povidone-iodine. After the surrounding area was covered, the sinus tract was examined by using a thin steel cane. The length and

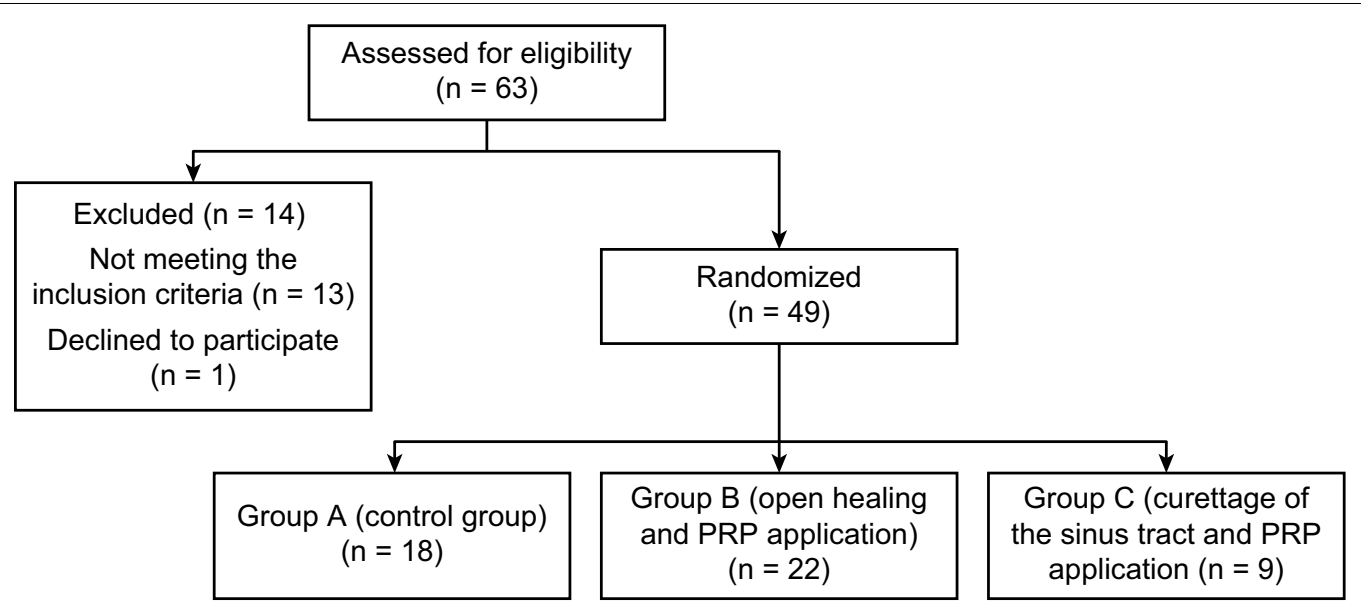

Fig. 1 CONSORT diagram 
width of the cavity were noted. Then, the sinus tract was removed, and the cavity volume was measured (Fig. 2).

\section{Minimally invasive surgery}

Minimally invasive surgery was performed under local anaesthesia in the operating room. The patient was prepared as for the open technique. The largest pit was excised, and all hairs in the cavity were removed with forceps (Fig. 3). Then, the whole tract was curetted meticulously and irrigated with saline solution. After haemostasis, the cavity volume was measured, and PRP was applied to the cavity.

For group $\mathrm{C}$, the cavity volume was low due to the nature of the operation. Therefore, we used a new parameter to standardize the cavity volume and wound-healing time. This new parameter was the recovery time per cavity (day/cc). A similar parameter was previously used in a study by Spyridakis et al. [5]. This ratio is the most objective parameter for comparison.

\section{Measurement of cavity volume}

The depth of the cavity was noted. Then, 50 cc of $0.9 \%$ saline solution was loaded into a syringe without inserting the needle into the tissue and added to the cavity until it filled the whole space, allowing the cavity volume to be measured accurately (Fig. 2). We didn't create any microtrauma during the measurement. The measurement was performed by subtracting the remaining volume of saline solution in the syringe from the total syringe volume, which was $50 \mathrm{cc}$.

\section{PRP administration}

After the cavity volume was measured with $0.9 \%$ saline solution, PRP was administered by filling the whole space from the lateral side of the cavity without creating any microtrauma. After the first application of PRP, the second dose was applied at $48 \mathrm{~h}$. Until that time, the dressing was not removed. Additional PRP was applied on the 3 rd, 4th and 5th days postoperatively.
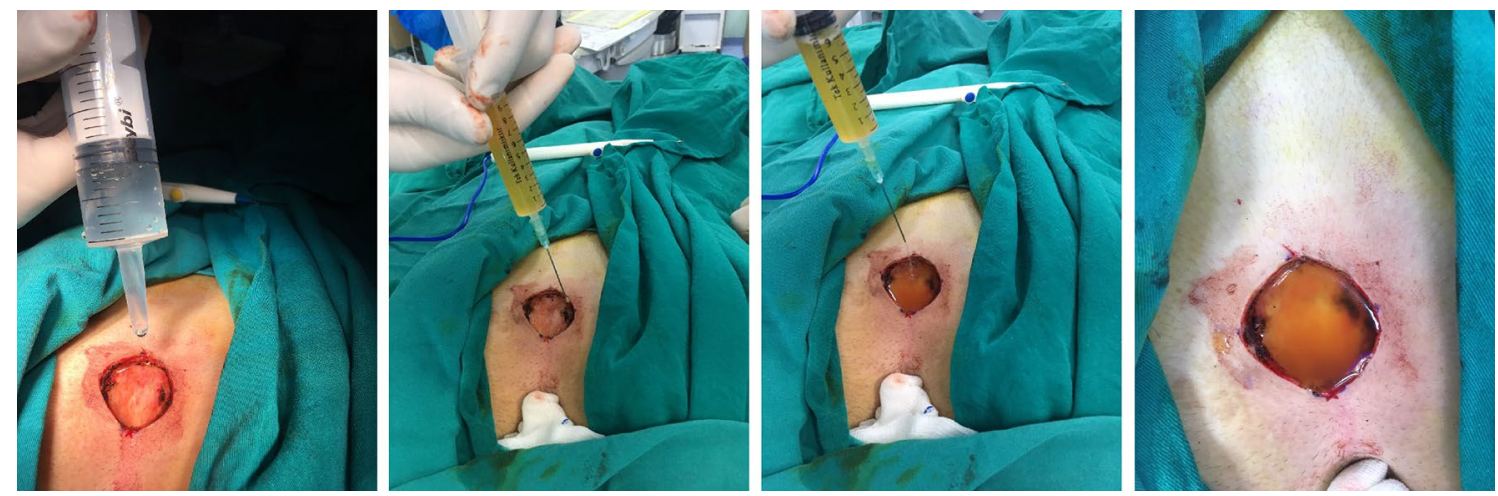

Fig. 2 Measurement of cavity volume and local PRP administration
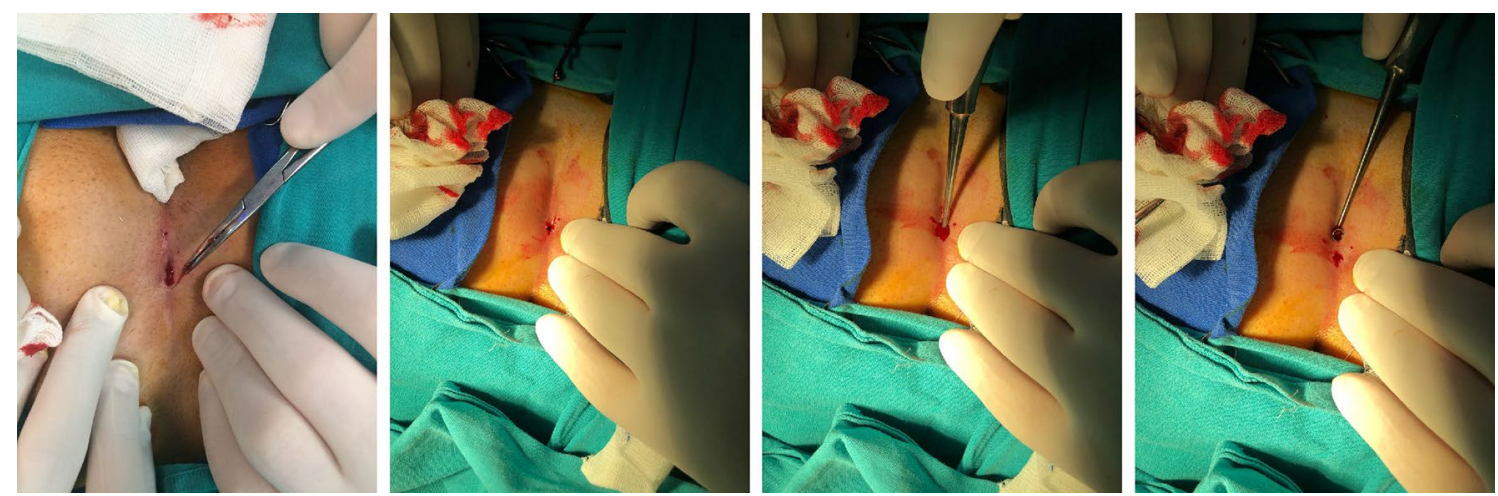

Fig. 3 Minimally invasive surgery 


\section{Preparation of PRP}

For clinical applications, good manufacturing practicecompliant human platelet concentrates can be created by the standard method for PRP production. Erythrocyte concentrate and platelet-containing plasma are separated by the first centrifugation, and platelet-poor plasma (PPP) and PRP/platelet concentrate are created by centrifuging the platelet-containing plasma a second time [6]. Platelets contain coagulation factors, growth factors (PDGF, TGF- $\beta 1$, IGF-1, VEGF, FGF-2) and interleukins (IL-1, IL-4, IL-6, IL-10, IL-13) [7].

We prepared the platelet concentrate by the PRP production method in the Hacettepe University Blood Center Laboratory, applying all standardized processes for healthy blood donors. In accordance with the "National Blood and Blood Components Preparation Use and Quality Assurance Guidelines", the requirements for PRP include a volume of at least $40 \mathrm{~mL}$, a minimum platelet count of $60 \times 10^{9} /$ unit [8], and a maximum leucocyte count of $0.2 \times 10^{9} /$ unit [9]. After approval, $450 \mathrm{cc}$ of blood was drawn from the patient by phlebotomy on the morning of surgery. A two-stage centrifugation method was used to separate the whole blood into its components. In the first stage, plasma was separated from erythrocyte concentrate by lowspeed centrifugation in a temperature-controlled Heraeus Cryofuge $6000 \mathrm{i}\left(22^{\circ} \mathrm{C}, 2500 \mathrm{rpm}, 7 \mathrm{~min}\right)$. After a 1-h waiting period, the second stage was initiated, in which the PRP/platelet concentrate was separated from the PPP by high-speed centrifugation $\left(22^{\circ} \mathrm{C}, 3200 \mathrm{rpm}\right.$, $15 \mathrm{~min}$ ). The $\mathrm{PRP} /$ platelet concentrate obtained after the second centrifugation step was shaken on an agitator for $1 \mathrm{~h}$ and divided into 5 equal parts with a sterile connection device (Fig. 4). We preserved the PRP at $25{ }^{\circ} \mathrm{C}$ on agitators. Before each dressing was placed, we applied a PRP aliquot to the wound with a syringe.

\section{Postoperative care}

All patients were discharged on the 1st postoperative day. Patients in all groups were advised not to uncover the wound for 2 days. If the patients experienced pain, they were advised to take the prescribed pain reliever no more than 2 times a day.

\section{Healing process}

At every postoperative visit, the cavity volume was measured. Wound healing time was standardized as the recovery time per unit of cavity volume (days/cc), an index that was previously used in the research of Spyridakis et al. [5].

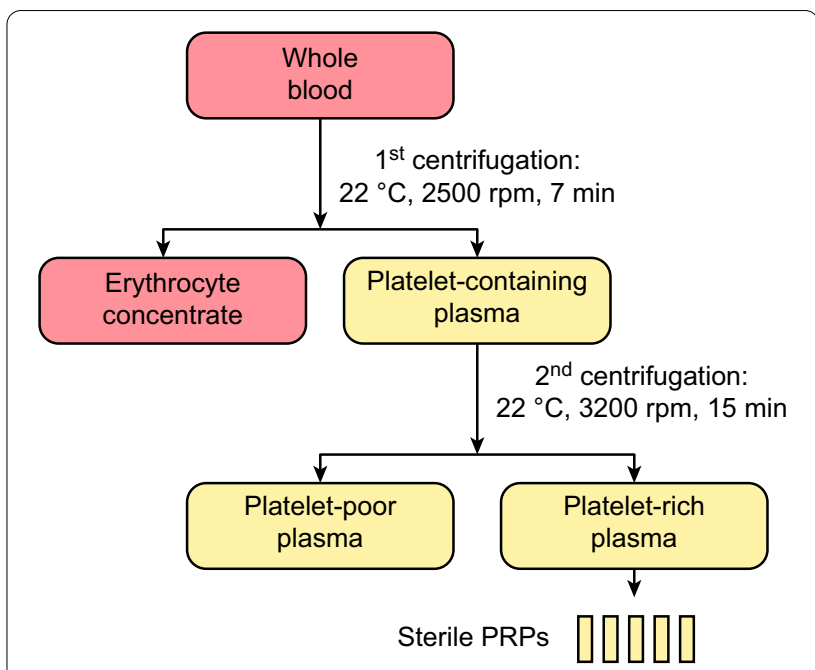

Fig. 4 PRP preparation steps

\section{Questionnaires}

The SF-36 and NHP questionnaires were applied to evaluate the patients' quality of life before and 3 weeks after surgery. We assessed the patients' general health, limitations, activities, physical health problems, emotional health problems, social engagement, pain, energy and emotions with the SF-36 questionnaire. Additionally, we evaluated the patients' pain, energy levels, emotional reactions, sleep, social isolation, and physical abilities of patients with the NHP questionnaire.

We used a visual analogue scale (VAS) to evaluate pain scores. This scale ranged from 0 to 10 , with higher scores indicating a stronger sensation of pain. The VAS scale was applied five times after surgery, on postoperative days $1,2,4,5$ and 21 . Patients were routinely prescribed dexketoprofen trometamol and advised to take it no more than 2 times a day. The number of tablets each patient took after the operation was recorded. The time interval until the patients became able to walk without pain (labelled herein as the "pain-free walking time") was recorded, as was the interval until the patients returned to their preoperative daily activities without any strain.

\section{Statistical analysis}

Nonparametric tests were used for hypothesis testing due to the small sample size and skewed data distribution. Numerical variables are summarized as the mean \pm standard deviation or as the median (minimum-maximum). Frequencies and percentages were used to summarize categorical variables. Three groups were compared with regard to demographic and clinical characteristics of patients using the Kruskal-Wallis test, 
Pearson's Chi-square test or Fisher's exact test. Dunn's post hoc test was performed to determine which groups were different from others after a Kruskal-Wallis test. Since pre- and postoperative observations of the same patient are dependent, we used a robust rank-based nonparametric method proposed by Bruner and Puri [10] for the analysis of longitudinal data in factorial contexts. With this method, relative treatment effects (RTEs) were given as descriptive point estimators. The $95 \%$ confidence intervals (CIs) of RTEs were also used to make post hoc inferences. If the related 95\% CIs did not overlap, we concluded that there was a significant difference between the time points or groups compared. The RTE is the probability that a randomly chosen observation from the time point and/or group under consideration has a larger value than a randomly chosen observation from the whole dataset regardless of the time point and/or group under consideration. The F1_LD_F1 design was used to analyse the repeated measurements taken from patients in the three groups. We tested three null hypotheses: no main effect of time, no main effect of group and no interaction effect of time and group. If the null hypothesis of no effect is true, every group and time point should have an RTE of 0.50. When the interaction effect is significant, it means that the trend in the observations over time is different between groups. When the main effect of time is significant, the observations differ across time points without regard for the group labels. When the main effect of group is significant, the observations differ across groups without regard for the time variable. All analyses were performed in R 3.4.4 (R Development Team), and the nparLD package was used for nonparametric repeated F1_LD_F1 design. A p value of $<0.05$ was considered to indicate a statistically significant difference $[11,12]$.

\section{Post hoc power analysis}

Power analysis was performed according to the primary aim of the study, which was to compare surgery groups (A, B, and C) in terms of healing parameters (Table 2). The power of the test was calculated as $98 \%$ for an effect size of $f=0.64$ (which is considered a large value and was calculated using the means in Table 2) and a Type I error rate of 0.05 , with the number of groups set to 3 and the sample sizes in the groups specified as 21,18 , and 9. Power analysis was performed using the G*Power v.3.1 program.

\section{Results}

Between March 2018 and January 2019, 49 of 63 recruited patients were included in the study, and 14 patients were excluded. There were 18 patients in group A, 22 patients in group B and 9 patients in group C. One
Table 1 Demographic characteristics of the patients

\begin{tabular}{lllll}
\hline & Group A & Group B & Group C & p \\
\hline Age (years) & $26.7 \pm 5.5$ & $24.7 \pm 5.5$ & $26.1 \pm 10$ & 0.400 \\
& $27(18-39)$ & $23.5(18-37)$ & $23(18-49)$ & \\
Gender & & & & 0.808 \\
$\quad$ Female & $4(22.2 \%)$ & $5(22.7 \%)$ & $1(11.1 \%)$ & \\
$\quad$ Male & $14(77.8 \%)$ & $17(77.3 \%)$ & $8(88.9 \%)$ & \\
Education level & & & & 0.004 \\
$\quad$ Primary & $1(5.6 \%)$ & 0 & $1(11.1 \%)$ & \\
$\quad$ High school & $7(38.9 \%)$ & $8(36.4 \%)$ & $5(55.6 \%)$ & \\
$\quad$ College & $10(55.5 \%)$ & $14(63.6 \%)$ & $3(33.3 \%)$ & \\
Chronic disease & $2(11.1 \%)$ & $4(18.2 \%)$ & $4(44.4 \%)$ & 0.153 \\
Chronic drug usage & $1(5.6 \%)$ & $2(9.1 \%)$ & $3(33.3 \%)$ & 0.136 \\
Family history of PS & $5(27.8 \%)$ & $6(27.3 \%)$ & $1(11.1 \%)$ & 0.750 \\
\hline
\end{tabular}

PS pilonidal sinus

Table 2 Healing parameters of the groups

\begin{tabular}{|c|c|c|c|c|}
\hline & Group A & Group B & Group C & $p$ \\
\hline Total number of pits & $\begin{array}{l}3.56 \pm 1.5 \\
3.5(1-8)\end{array}$ & $\begin{array}{l}3.6 \pm 1.5 \\
3(1-8)\end{array}$ & $\begin{array}{l}2.0 \pm 0.7 \\
2(1-3)\end{array}$ & $0.004^{\beta, \gamma}$ \\
\hline Cavity volume (cc) & $\begin{array}{l}18.8 \pm 8.2 \\
18(8-39)\end{array}$ & $\begin{array}{l}22.6 \pm 11.5 \\
21(5-45)\end{array}$ & $\begin{array}{l}4.0 \pm 1.4 \\
4(2-7)\end{array}$ & $<0.001^{\beta, Y}$ \\
\hline $\begin{array}{l}\text { Wound healing time } \\
\text { (day) }\end{array}$ & $\begin{array}{l}54.4 \pm 24.3 \\
48(23-114)\end{array}$ & $\begin{array}{l}37.1 \pm 16.6 \\
34(16-81)\end{array}$ & $\begin{array}{l}13.9 \pm 6.6 \\
11(8-28)\end{array}$ & $<0.001^{\beta, \gamma}$ \\
\hline $\begin{array}{l}\text { Recovery time per } \\
\text { unit of cavity volume } \\
\text { (days/cc) }\end{array}$ & $\begin{array}{l}2.9 \pm 0.6 \\
2.9(2-4)\end{array}$ & $\begin{array}{l}1.8 \pm 0.7 \\
1.5(0.8-3.6)\end{array}$ & $\begin{array}{l}3.8 \pm 2.1 \\
3.5 \\
(1.8-7)\end{array}$ & $<0.001^{a, y}$ \\
\hline
\end{tabular}

${ }^{a}$ There was a significant difference between Group A and Group B after post hoc analysis

${ }^{\beta}$ There was a significant difference between Group A and Group $C$ after post hoc analysis

${ }^{Y}$ There was a significant difference between Group B and Group $C$ after post hoc analysis

patient in group $\mathrm{C}$ was excluded because this participant was lost to follow-up. There was no significant difference in the demographic characteristics of the patients by group (Table 1).

The healing parameters of the groups are shown in Table 2. While the cavity volume did not differ between groups A and B $(18.8 \pm 8.2$ cc vs. $22.6 \pm 11.5$ cc; $\mathrm{p}=0.393$ ), the recovery time per unit of cavity volume was significantly faster in group B than in group A $(p<0.001)$ (Fig. 5). However, there was no significant difference between group A and group B regarding wound-healing time $(\mathrm{p}=0.092)$. Despite the minimally invasive technique and reduced cavity volume in group $\mathrm{C}$, the recovery time per unit volume was slower in that group than in the other two ( 2.9 vs. 1.8 vs. 3.8 days/cc for groups $\mathrm{A}, \mathrm{B}$, and $\mathrm{C}$, respectively; $\mathrm{p}<0.001$ ).

In the postoperative period, the need for painkillers was significantly lower in group B and group $C$ than in 


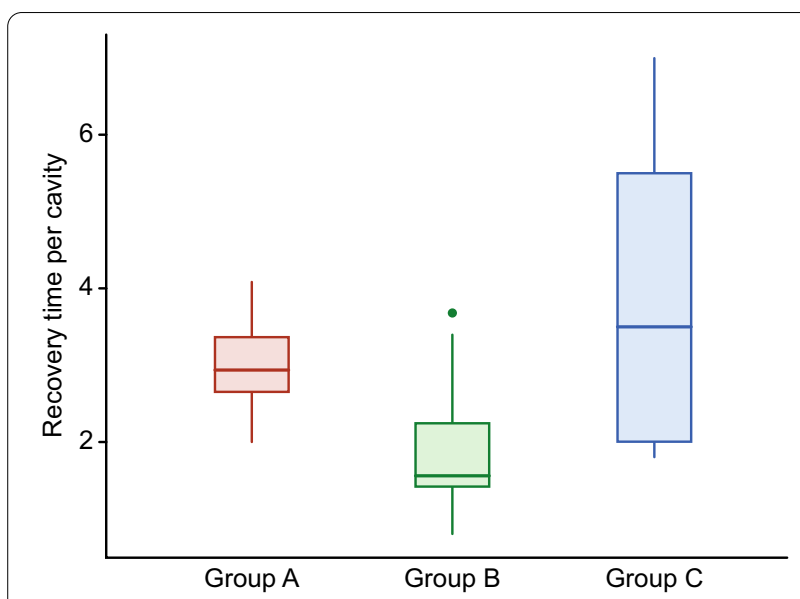

Fig. 5 Recovery time per unit of cavity volume (day/cc)

group A ( $\mathrm{p}=0.003$ and $\mathrm{p}<0.001$, respectively). Additionally, the time required to return to normal activity was significantly shorter in both PRP groups ( $B$ and $C$ ) than in group $\mathrm{A}(\mathrm{p}=0.003$ and $\mathrm{p}<0.001$, respectively) (Table 3$)$.

When VAS scores were compared, it was found that there was no significant difference in these scores on the 1 st day. When the difference between groups was investigated by measurement time, it was determined by testing whether the RTEs intersected the 95\% CIs (Fig. 6). From visit 2 to visit 5 , the VAS scores group B and group $\mathrm{C}$ were significantly lower than those of group $\mathrm{A}$. There was no significant group difference in preoperativepostoperative changes in SF-36 or NHP quality-of-life scores. However, when the pain and general health perception parameters of the SF-36 were considered in isolation, these parameters were observed to be significantly improved in group B from the preoperative to the postoperative period.

All patients were followed up for 6 months. There were no recurrences of disease in any of the groups. Four patients in group $C$ had abscesses after the fifth PRP dose was applied (Additional file 1).

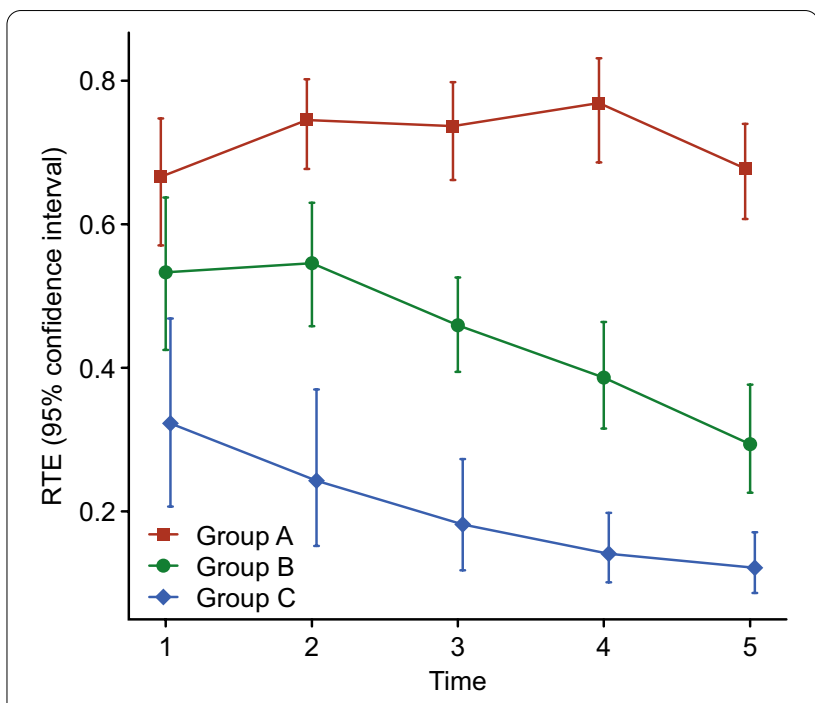

Fig. 6 Graph showing VAS scores by RTE. If the relevant 95\% Cls did not overlap, we concluded that there was a significant difference between the time points or groups compared

\section{Discussion}

Both PS disease and its treatment process can cause some complications. For example, pain during dressing changes, bad odour during the healing process and fear of recurrence of the disease cause serious concern in patients $[13,14]$. Therefore, the optimal treatment modality for patients should be painless, allowing them to return to their daily activities quickly and with a minimal recurrence rate [15]. However, surgeons are still working to determine the most appropriate method, evaluating minimally invasive methods and various other treatments [16]. Recently, there has been an emphasis on imaging and physical examination studies aiming to provide objective criteria in the diagnosis, treatment and follow-up of PS [17].

The present study compared the effectiveness PRP with that of conventional moist dressings and included a third

Table 3 Comparison of the patients with respect to the use of painkillers, pain-free walking time, and time taken to return to daily activities

\begin{tabular}{|c|c|c|c|c|}
\hline & Group A & Group B & Group C & $\mathbf{p}$ \\
\hline Quantity of painkillers needed & $\begin{array}{l}9.5 \pm 4.3 \\
10(0-14)\end{array}$ & $\begin{array}{l}3.4 \pm 2.5 \\
4(0-10)\end{array}$ & $\begin{array}{l}0.1 \pm 0.3 \\
0(0-1)\end{array}$ & $<0.001^{\alpha, \beta, \gamma}$ \\
\hline Pain-free walking time & $\begin{array}{l}6.4 \pm 2.3 \\
6(3-12)\end{array}$ & $\begin{array}{l}5.3 \pm 2.3 \\
6(1-12)\end{array}$ & $\begin{array}{l}2.7 \pm 0.7 \\
3(2-4)\end{array}$ & $<0.001^{\beta, y}$ \\
\hline Time taken to return to daily activities & $\begin{array}{l}16.3 \pm 5.6 \\
15.5(7-30)\end{array}$ & $\begin{array}{l}9.0 \pm 4.5 \\
8(3-20)\end{array}$ & $\begin{array}{l}3.0 \pm 1.1 \\
3(2-5)\end{array}$ & $<0.001^{\alpha, \beta, y}$ \\
\hline
\end{tabular}

a There was a significant difference between Group A and Group B after post hoc analysis

${ }^{\beta}$ There was a significant difference between Group $A$ and Group $C$ after post hoc analysis

${ }^{\gamma}$ There was a significant difference between Group B and Group $C$ after post hoc analysis 
group (the minimally invasive group) that was not found in previous studies on PRP application in PS disease. With or without PRP, we favour the open healing process because of the low recurrence rate [13]. The aim of our study was to evaluate the effect of PRP on the woundhealing process in the PS cavity after surgery. An accelerated recovery time reduces the risk of infection in the surgical region and would reduce the loss of productive work hours [5]. Additionally, we aimed to assess the level of pain following each procedure.

The primary end point of this study was the completion of wound healing, which was significantly faster in group $B$ and group $C$ than in group $A$. However, this parameter is not objective enough because there was a considerable difference in cavity volume between groups. When we compared the cavity volumes among all three groups, there was no significant difference between group A and group $B$, whereas in group $C$, the cavity volume was found to be significantly lower due to the nature of the surgical technique. Therefore, we needed an objective parameter to compare the complete wound-healing times of group B and group C. For this purpose, we used the recovery time per unit of cavity volume. This index represents the number of days required for each $1 \mathrm{cc}$ of cavity volume to be filled. We found that the recovery time per unit of cavity volume was 2.9 days/cc in group A, 1.8 days/cc in group B and 3.8 days/cc in group C. We believe that the reason group $\mathrm{C}$ needed more recovery time per unit volume despite the small absolute volume was that the PRP was trapped in the cavity and was not dispersed and drained sufficiently. We believe this is the reason why 4 patients in this group had abscesses in the 2nd week of follow-up. Since there was an almost 50\% incidence of abscess development, patient admission to group $\mathrm{C}$ was stopped, and the study was continued with the other two groups (group A and group B).

PRP treatment gained popularity in regenerative medicine and other fields with the publication of early outcomes of its use in maxillofacial surgery and cardiac surgery in 1980-1990 [18, 19]. PRP has been shown to significantly accelerate the recovery process, especially in tissues with weak blood flow and slow cell cycles, such as tendons, ligaments and cardiac tissues [20,21]. Sun et al. evaluated the therapeutic effects of autologous PRP on deep partial-thickness burns in Bama pigs. Their data showed that the time to wound re-epithelialization was shortened in the PRP group [22]. In another study, PRP was combined with chitosan and silk fibroin to prevent the activity of proteases in the wound microenvironment, and this preparation was applied to diabetic ulcers. It was determined that repair cells proliferated rapidly under similar conditions in vitro, and angiogenesis and nerve repair were accelerated in vivo [23]. There are also studies investigating the preventive effect of PRP on anastomotic leaks based on its positive effect on wound healing. In such a study on rats, the effect on anastomotic leakage after intraperitoneal chemotherapy was investigated, and anastomotic burst pressure was found to be significantly different in the PRP group [24].

PRP exerts an effect on the wound-healing process locally by delivering growth factors and cytokines to the wound area; these are the main elements of healing in the stages of inflammation, proliferation and remodelling [25]. Growth factors are proteins that serve as signalling molecules for cells. The main source of growth factors in PRP is platelets. Platelet-derived growth factor (PDGF) stimulates cell replication and promotes angiogenesis, epithelization, and granulation tissue formation. Vascular endothelial growth factor (VEGF) promotes angiogenesis. Epidermal growth factor (EGF) promotes cell differentiation and stimulates re-epithelization, angiogenesis and collagenase activity. Fibroblast growth factor (FGF) promotes the proliferation of endothelial cells and fibroblasts and stimulates angiogenesis. Transforming growth factor beta (TGF- $\beta$ ) 2 and 3 promote the formation of the extracellular matrix [26-30].

The comparison of VAS scores revealed different trends in the three groups over time. The reduction in pain in group $B$ and group $C$ from the 2nd day onward suggests that the analgesic effect of PRP started after the 24th hour postoperatively. The low VAS scores beginning on the second day reduced the need for painkillers. There have been only a few studies on the use of PRP in PS; these studies evaluated the effect of PRP application on the wound-healing process, pain and the ability to return to daily activities after open surgery $[5,31]$. In both studies, wound-healing time, pain scores and time to return to daily activities were more favourable in the PRP-treated group than in the non-PRP-treated control group. These results are in line with the findings in our study, showing a rapid return to daily activity, low pain scores and rapid wound healing. Furthermore, the effectiveness of PRP as an analgesic has been demonstrated in painful conditions such as osteoarthritis and trochanteric pain syndrome [32, 33].

The SF-36 and NHP questionnaires were also evaluated based on 95\% CIs of the RTEs. When the questionnaire results were evaluated globally, no significant difference was detected between the preoperative and postoperative periods. However, when we considered the subscales of the SF-36 separately, we found confirmation of the effect of PRP on pain. SF-36 pain scores were significantly improved in group B. Additionally, in this group, the general health perception parameter of the SF-36 was significantly improved. While differences were found in these two parameters, no significant differences were identified 
in the other six parameters of psychological distress assessed by the SF-36. In the study of Spyridakis et al., when global SF-36 scores were evaluated, it was found that the PRP group had a lower level of psychological distress than the control group [5].

\section{Limitations}

This study has several potential limitations, which need to be addressed in future studies. We are aware that the present study had a smaller sample than other, similar studies. In addition, group $\mathrm{C}$ had fewer patients than either of the other groups because we stopped allocating patients to group $\mathrm{C}$ due to the high rate of postoperative abscess formation. The absence of a minimally invasive non-PRP-treated control for group $C$ is another limitation. Cost-effectiveness and cost-benefit analyses were not performed because the main goal of the study was not to evaluate these parameters. Another limitation is that the patient follow-up times varied between 6 and 18 months.

\section{Conclusion}

In the treatment of PS disease, PRP application improves postoperative recovery in that it speeds patients' return to daily activities, reduces their pain scores and increases their quality of life.

The use of PRP for wound care during postoperative healing by secondary intention should be considered in the surgeon's armamentarium for the management of PS disease.

\section{Abbreviations \\ PRP: Platelet-rich plasma; PS: Pilonidal sinus; GFs: Growth factors; SF-36: Short Form-36; NHP: Nottingham Health Profile; VAS: Visual Analogue Scale; PPP: Platelet-poor plasma; PDGF: Platelet-derived growth factor; EGF: Epidermal growth factor; IGF-1: Insulin-like growth factor-1; VEGF: Vascular endothelial growth factor; FGF-2: Fibroblast growth factor-2; TGF- $\beta$ : Transforming growth factor beta; IL-1: Interleukin-1; IL-4: Interleukin-4; IL-6: Interleukin-6; IL-10: Interleukin-10; IL-13: Interleukin-13; RTEs: Relative treatment effects; Cls: Confidence intervals}

\section{Supplementary Information}

The online version contains supplementary material available at https://doi. org/10.1186/s12893-021-01370-5.

Additional file 1. : Consent Form and Follow-up Form.

\section{Acknowledgements}

Not applicable.

Statement: Selected for an e-poster presentation at the American Society of Colon and Rectal Surgeons Annual Scientific Meeting, Boston, MA, June $6-10,2020$.

\section{Authors' contributions}

Substantial contributions to the conception and design, acquisition ofdata, or analysis and interpretation of data: CYB, TKA, CB, MAK, BDE, OIO, CA, MA
Kuzu. Drafting the article or contributing important intellectual: CYB, TKA, CB, MAK, BDE, OIO, CA, MAK. Content: CYB, TKA, CB, BDE, CA. Critical revision of the manuscript and final approval of the version to be published: CA, MAK. All authors read and approved the final manuscript.

\section{Funding}

No funding supported this work.

Availability of data and materials

The datasets used and analysed during the current study are available from the corresponding author upon reasonable request.

\section{Declarations}

\section{Ethics approval and consent to participate}

This study was conducted in accordance with the Declaration of Helsinki and was started after approval from the Ethics Committee of the Ankara University Medicine Faculty in Ankara (Approval Number: 03-162-18). The current study is also registered on the public website ClinicalTrials.gov (ClinicalTrials.gov Identifier Number: NCT04697082; date: 05/01/2021). Informed consent was obtained from all the participants.

\section{Consent for publication}

Informed consent was obtained from all the participants.

\section{Competing interests}

The authors declare no competing interests.

\section{Author details}

'Department of Surgery, Ankara University Faculty of Medicine, Ankara, Turkey. ${ }^{2}$ Department of Hematology, Hacettepe University Faculty of Medicine, Ankara, Turkey. ${ }^{3}$ Department of Biostatistics, Ankara University Faculty of Medicine, Ankara, Turkey.

Received: 24 April 2021 Accepted: 11 October 2021

Published online: 21 October 2021

\section{References}

1. Chintapatla S, Safarani N, Kumar S, Haboubi N. Sacrococcygeal pilonidal sinus: historical review, pathological insight and surgical options. Tech Coloproctol. 2003;7:3-8. https://doi.org/10.1007/s101510300001.

2. López JJ, Cooper JN, Halleran DR, Deans KJ, Minneci PC. High rate of major morbidity after surgical excision for pilonidal disease. Surg Infect. 2018. https://doi.org/10.1089/sur.2018.020.

3. Man D, Plosker H, Winland-Brown JE. The use of autologous platelet-rich plasma (platelet gel) and autologous platelet-poor plasma (fibrin glue) in cosmetic surgery. Plast Reconstr Surg. 2001;107:229-37. https://doi.org/ 10.1097/00006534-200101000-00037 (discussion 238-229).

4. Microsoft $^{\circledR}$ Excel $^{\circledR} 2008$ for Mac Version $12.0(071130)$

5. Spyridakis M, Christodoulidis G, Chatzitheofilou C, Symeonidis D, Tepetes $\mathrm{K}$. The role of the platelet-rich plasma in accelerating the wound-healing process and recovery in patients being operated for pilonidal sinus disease: preliminary results. World J Surg. 2009;33:1764-9. https://doi.org/ 10.1007/s00268-009-0046-y

6. Burnouf T, Strunk D, Koh MB, Schallmoser K. Human platelet lysate: replacing fetal bovine serum as a gold standard for human cell propagation? Biomaterials. 2016;76:371-87. https://doi.org/10.1016/j.biomaterials. 2015.10.065.

7. Xiong G, Lingampalli N, Koltsov JCB, et al. Men and women differ in the biochemical composition of platelet-rich plasma. Am J Sports Med. 2018:46:409-19. https://doi.org/10.1177/0363546517740845.

8. De Pascale MR, Sommese L, Casamassimi A, Napoli C. Platelet derivatives in regenerative medicine: an update. Transfus Med Rev. 2015;29:52-61. https://doi.org/10.1016/j.tmrv.2014.11.001.

9. Ulusal Kan ve Kan Bileşenleri Hazıllama Kullanım ve Kalite Güvencesi Rehberi. 2016. https://kanver.org/Upload/Dosya/ulusal_kan rehberi.pdf.

10. Brunner E, Puri ML. Nonparametric methods in factorial designs. Stat Pap. 2001:42:1-52. https://doi.org/10.1007/s003620000039. 
11. The R Development Core Team. A language and environment for statistical computing. Vienna: R Foundation for Statistical Computing; 2018.

12. Noguchi K, Gel YR, Brunner E, Konietschke F. nparLD: an r software package for the nonparametric analysis of longitudinal data in factorial experiments. J Stat Softw. 2012. https://doi.org/10.18637/jss.v050.i12.

13. Mahdy T. Surgical treatment of the pilonidal disease: primary closure or flap reconstruction after excision. Dis Colon Rectum. 2008;51(12):181622. https://doi.org/10.1007/s10350-008-9436-8.

14. Bradley $L$. The lived experience of young adults with chronic pilonidal sinus disease: a phenomenological approach. Poster presentation at the World Union of Wound Healing Societies Conference, Paris, France, July 8-13, 2004.

15. Solla JA, Rothenberger DA. Chronic pilonidal disease: an assessment of 150 cases. Dis Colon Rectum. 1990;33:758-61.

16. Velotti N, Manigrasso M, Di Lauro K, Araimo E, Calculli F, Vertaldi S, Sosa Fernandez LM. Minimally invasive pilonidal sinus treatment: a narrative review. Open Med. 2019;14(1):532-6. https://doi.org/10.1515/ med-2019-0059.

17. Yavuz Y, Yıldırım MA, Cakir M, Varman A, Karahan O. Classification of pilonidal sinus disease according to physical examination, ultrasonography and magnetic resonance imaging findings. Turk J Colorectal Dis. 2020;30(4):261-7.

18. DelRossi AJ, Cernaianu AC, Vertrees RA, et al. Platelet-rich plasma reduces postoperative blood loss after cardiopulmonary bypass. J Thorac Cardiovasc Surg. 1990;100:281-6. https://doi.org/10.1016/S0022-5223(19) 35569-2.

19. Ferrari M, Zia S, Valbonesi M, et al. A new technique for hemodilution, preparation of autologous platelet-rich plasma and intraoperative blood salvage in cardiac surgery. Int J Artif Organs. 1987;10:47-50. https://doi. org/10.1177/039139888701000111.

20. Boswell SG, Cole BJ, Sundman EA, Karas V, Fortier LA. Platelet-rich plasma: a milieu of bioactive factors. Arthroscopy. 2012;28:429-39. https://doi. org/10.1016/j.arthro.2011.10.018.

21. Sánchez M, Anitua E, Azofra J, Andía I, Padilla S, Mujika I. Comparison of surgically repaired Achilles tendon tears using platelet-rich fibrin matrices. Am J Sports Med. 2007;35:245-51. https://doi.org/10.1177/03635 46506294078.

22. Sun Y, Cao Y, Zhao R, Xu F, Wu D, Wang Y. The role of autologous PRP on deep partial-thickness burn wound healing in bama pigs. J Burn Care Res. 2020;41(3):657-62.

23. Qian Z, Wang H, Bai Y, Wang Y, Tao L, Wei Y, Fan Y, Guo X, Liu H. Improving chronic diabetic wound healing through an injectable and self-Healing hydrogel with platelet-rich plasma release. ACS Appl Mater Interfaces. 2020;12(50):55659-74.

24. Buk OF, Ocak S, Genc B, Avcı B, Uzuner HO. Is platelet-rich plasma improves the anastomotic healing in hyperthermic intraperitoneal chemotherapy with oxaliplatin: an experimental rat study. Ann Surg Treat Res. 2020;98(2):89-95.

25. Broughton G, Janis JE, Attinger CE. Wound healing: an overview. Plast Reconstr Surg. 2006;117:1e-S-32e-S. https://doi.org/10.1097/01.prs.00002 22562.60260.f9.

26. Rudkin GH, Miller TA. Growth factors in surgery. Plast Reconstr Surg. 1996;97:469-76. https://doi.org/10.1097/00006534-199602000-00032.

27. Frazier SK, Higgins J, Bugajski A, Jones AR, Brown MR. Adverse reactions to transfusion of blood products and best practices for prevention. Crit Care Nurs Clin N Am. 2017;29:271-90. https://doi.org/10.1016/j.cnc.2017. 04.002

28. Harewood J, Master SR. Transfusion, hemolytic reaction. Treasure Island: StatPearls Publishing; 2017.

29. Rauch C, Feifel E, Amann EM, et al. Alternatives to the use of fetal bovine serum: human platelet lysates as a serum substitute in cell culture media. Altex. 2011;28:305-16. https://doi.org/10.14573/altex.2011.4.305.

30. Lange C, Cakiroglu F, Spiess AN, Cappallo-Obermann H, Dierlamm J, Zander AR. Accelerated and safe expansion of human mesenchymal stromal cells in animal serum-free medium for transplantation and regenerative medicine. J Cell Physiol. 2007;213:18-26. https://doi.org/10.1002/ jcp.21081.

31. Mehrabi Bahar M, Ali Akbarian M, Azadmand A. Investigating the effect of autologous platelet-rich plasma on pain in patients with pilonidal abscess treated with surgical removal of extensive tissue. Iran Red Crescent Med J. 2013;15:e6301. https://doi.org/10.5812/ircmj.630.

32. Ribeiro AdG, Junior WR, Silva ARNSE, Polesello GC, Guimarães RP. PRP in the treatment of trochanteric syndrome: a pilot study. Acta Ortop Bras. 2016;24(4):208-12. https://doi.org/10.1590/1413-785220162404159837.

33. Taniguchi Y, Yoshioka T, Kanamori A, Aoto K, Sugaya H, Yamazaki M. Intra-articular platelet-rich plasma (PRP) injection for treating knee pain assosiated with osteoarthritis of the knee in the Japanese population: a phase I and Ila clinical trial. Nagoya J Med Sci. 2018;80(1):39-51. https:// doi.org/10.18999/nagjms.80.1.39.

\section{Publisher's Note}

Springer Nature remains neutral with regard to jurisdictional claims in published maps and institutional affiliations.
Ready to submit your research? Choose BMC and benefit from:

- fast, convenient online submission

- thorough peer review by experienced researchers in your field

- rapid publication on acceptance

- support for research data, including large and complex data types

- gold Open Access which fosters wider collaboration and increased citations

- maximum visibility for your research: over $100 \mathrm{M}$ website views per year

At BMC, research is always in progress.

Learn more biomedcentral.com/submissions 